\title{
Informal WEEE Recycling in China: A Field Study of Stakeholders in Tianjin
}

\author{
Xian Li, Miles Park, and Oya Demirbilek
}

\begin{abstract}
Waste of electrical and electronic equipment (WEEE or e-waste) collection and recycling operation in China has been dominated by informal recyclers, whose recycling activities have caused serious negative impacts. This study is based on small-scaled interviews and observational studies that examine the characteristics of two groups of informal collectors and the relationships between relevant stakeholders. The stakeholders involved in this study include informal door-to-door collectors, ICT street traders, repair shops, collection and distribution centers. Several conclusions have been derived from the study: 1) the informal recycling sector has several prominent features including self-organized and market-driven operations, cheap labor and low-cost transportation; 2) End of life (EOL) large household appliances and Information and Communications Technology Products (ICT) are processed by two separate but parallel systems based on two different groups of collectors: door-to-door collectors and ICT street traders; 3) PCs and large household appliances are the most wanted appliances for informal door-to-door collectors in any condition whereas ICT products can be resold only in good-condition; 4) city-based informal collection sector has many advantages over the regulated recycling system and should be retained.
\end{abstract}

Index Terms - e-waste, WEEE, informal recycling, informal collectors, unregulated recycling.

\section{INTRODUCTION}

According to literature reviews worldwide, there are three categories of collection methods that organized by three main sectors: producer, municipality and independent collector [1-3]. In China, electronic waste collection and recycling systems are dominated by a high level of independent informal recyclers [4-6]. The unregulated informal recycling is practiced without any environmental control concerns. There are many poor regions in China, where recover materials from e-waste by very rudimentary tools and methods. Their recycling activities have released considerable amounts of toxic substances, which have led to severe negative impacts to the environment and human health [7-9]. In order to mitigate these environmental consequences, the Chinese government has made unremitting efforts in proposing legislative reforms, establishing national recycling plants $[10,11]$ and launching regulated collection schemes

Manuscript received September 1, 2012; revised October 24, 2012

Xian Li is with University of New South Wales, Faculty of the Built Environment, Sydney, Australia (e-mail: fairylixian@gmail.com).

Miles Park is with the Faulty of Built Environment at University of New South Wales, Sydney, Australia (e-mail: milesp@unsw.edu.au).

Oya Demirbilek is with the Industrial Design Program at University of New South Wales, Faculty of the Built Environment, Sydney, Australia (e-mail: o.demirbilek@unsw.edu.au).
[10-13]. All the official attempts indicate that the biggest challenge of WEEE management in China comes from the competition created by the informal collectors. In order to propose effective strategies to reduce the negative impacts resulting from informal recycling activities, it is necessary to identify the significance of informal collection system.

Informal sectors that involved in collection system are characterized by being small-scale, labor-intensive, and operating beyond the supervision of different levels of official governances [14-17]. In view of the unregulated nature of informal collectors who keep changing locations, very few studies have been conducted to specifically identify or describe informal collectors or relevant stakeholders. In addition to the informal collectors, the present study targets a group of ICT traders, which group of traders has developed for several years but lack of attentions in previous studies. This group of collectors specifically collects good-conditioned ICT products for reuse purposes, named ICT street traders in this study.

The stakeholders for informal recycling involved in this study include two groups of informal collectors and relevant connecting sectors such as repair shops, component supplier shops, and collection and distribution centers. A part of the study was undertaken with photographic observations and small group interviews, in an attempt to identify the significance of informal recycling systems, as well as the different relationships between relevant stakeholders.

\section{RESEARCH DESIGN}

This study was conducted in the city of Tianjin, where exists mixed recycling operations involving both formal and informal systems. Tianjin is a pilot city to develop national recycling projects. There are 6 large scale national recycling plants that have been established in Tianjin before 2011, and there are only 21 of them nationwide by then [10]. Additionally, Tianjin is one of the pilot cities of the new trade-in scheme [18]. In addition to the development of regulated collection and recycling projects in Tianjin, the conventional informal recycling sectors in Tianjin are also well-developed due to the variety of e-waste resources. There are studies indicated that Tianjin is the major target area to accept these e-waste, which is exported illegally by Japan [19]. Besides the imported e-waste, e-waste that generated from local residents, manufactures and institutions in Tianjin also produce considerable amounts of resources for both formal and informal recycling systems.

The field study begins with small-scaled interviews with two groups of informal collectors: individual collectors and ICT street traders. The first part of interview aims to identify 
the basic characteristics and distinctions of these two groups of collectors and investigates the directions of waste streams. The second part of the study includes an on-site observational study with stakeholders that indicated receiving e-waste from collectors. The choice of locations in the second part resulted directly from the interview part. Given the unregulated nature of informal sectors, as well as personal security issues for the researchers in remote areas, the study had to be conducted discreetly, by either tactfully asking questions or privately taking photos.

After a difficult recruitment process, the study involved more than twenty repair shops (from four second-hand market sites), two collection and distribution centers, four component supplier shops, five individual collectors and three ICT street traders.

\section{SURVEY RESULTS}

\section{A. Informal Collectors}

Most informal door-to-door collectors travel around communities, looking for customers by their low-cost transportation such as tricycles, bicycles, and electric vehicles. From the observation study, (auto) tricycles are the most common vehicles used by collectors because they are cost-effective and capable of carrying large household appliances. Informal collectors normally have signage boards displaying the categories of waste they want to collect. In addition to electronic products, many collectors accept all kinds of recyclable materials such as newspapers, plastic bottles and cans. Also from the observation study, this group of collectors is mainly characterized by middle-aged males because it requires physical strength when moving large appliances. Fig. 1 is a door-to-door collector and his collected e-waste.

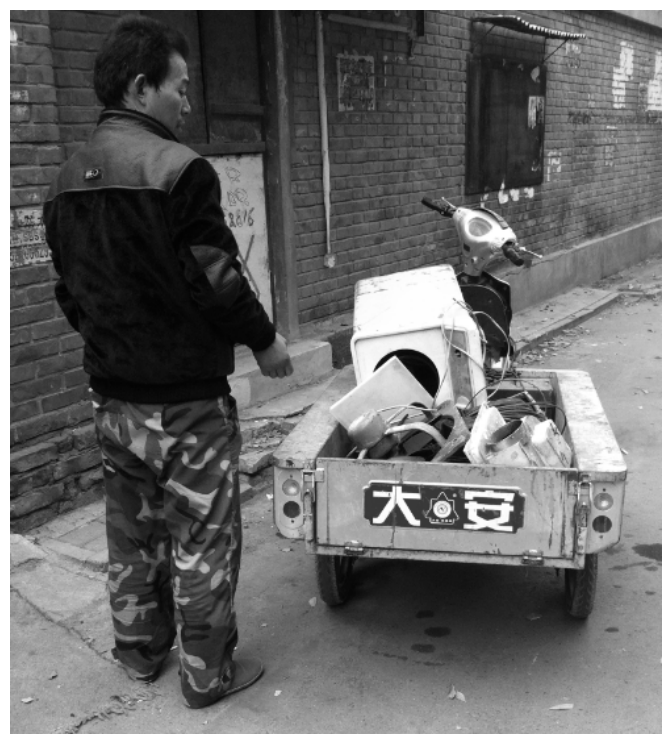

Fig. 1. An informal door-to-door collector and his collected e-waste.

Besides the above-described general characteristics, informal collectors have collection preferences on WEEE categories. PCs are the most wanted appliances, followed by other large appliances such as TVs, refrigerators, washing machines, and air conditioners. Interviewers claimed that these popular items on any condition are normally offered at higher prices for end-users, because they normally contain valuable components, such as the compressors in refrigerators or air conditioners, and the electrical motors in washing machines. "Even without valuable components, large appliances will result in more materials after dismantling," stated by collector A. By contrast, smaller electronic products such as mobile phones, radios, stereo sounds always be traded at lower prices. "We don't offer good price for those small products. In most cases, we do not know how to identify the valuable parts and just sell them by the weight", said by collector B. Due to such reduced demand of small equipment from door-to-door collectors, many households offer small devices for free. In such cases, collectors are willing to accept all products because they can sell them by the weight in the worst situation.

Besides the size and the valuable components within products, their overall condition depends upon functionality, age and brand. All the preferences of informal collectors rely on the market demands.

After collected from households, EOL products are sold to the best bidder. Fig. 2 illustrates the five operations and related downstream stakeholders. Some collectors sell products without processing while some collectors dismantle large appliances into pieces and sell components and recyclable materials respectively to different bidders. As a result, the revenue earned by informal collectors can come from one or more of five operations.

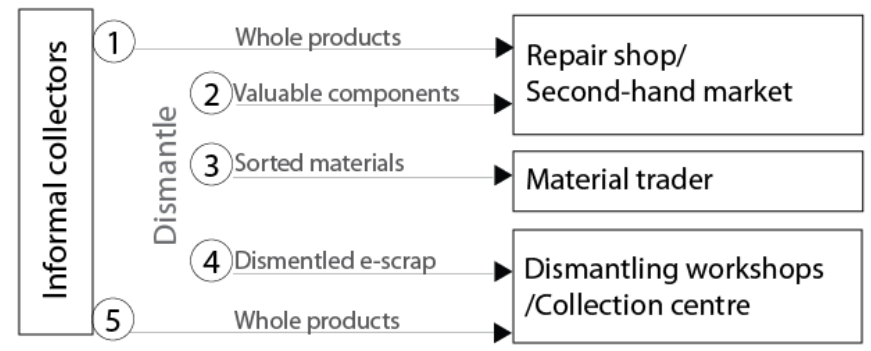

Fig. 2. WEEE distributions from door-to-door collectors.

From the interview study, local stakeholders that directly trade with the door-to-door collectors involves repair shops and collection sites, whose businesses are mostly located in less-developed regions around the city of Tianjin such as Liu fang zi, Qing guang, Wang zhuang, Wei guo road, Zhao gu li, and Tian mu.

\section{B. ICT Street Traders}

Many EOL products are still functional when being obsoleted, particularly for the electronic products [20, 21]. It's indicated by the door-to-door collectors that they are reluctant to accept the small electronic products no matter in what condition. Given the rapid obsolescence of ICT products and the high demand of second-hand markets in China, ICT street traders are developed as an important disposal method for households. The traders specifically purchase good-condition ICT products from individuals. The observational study allowed for the identification of several characteristics of the two groups of collectors. Compared with door-to-door collectors, the ICT street traders have several differences, which are as follows: 
1) Location: unlike the door-to-door collectors who travel around communities, ICT street traders are normally located around shopping centers and electronic products stores. The ICT traders operate between customers and repair shops through the quick turnover of trading products. Their convenient locations enable customers to dispose of their old products just when they bought new ones. Similar to informal collectors, they do not have an established location, and they often have simple signage boards displaying the WEEE categories they intend to collect. Fig 3 is an ICT street trader and his signature board.

2) Limited range of e-waste collection categories: compared to the comprehensive range of categories collected by door-to-door collectors, ICT traders only collect specifically ICT products and peripherals. These include mobile phones, PCs, monitors, main boards, printers, computer memory components, and flash cards. As indicated by the interviewed ICT traders, PCs are also the most wanted appliances. Additionally, mobile phones are the most common products they have received.

3) Resell, repair and component reuse: ICT street traders only collect items with potential reuse value. Therefore, out-of-date equipment has no value to them, even if it works. According to such criterions, old products only offered with very low prices.

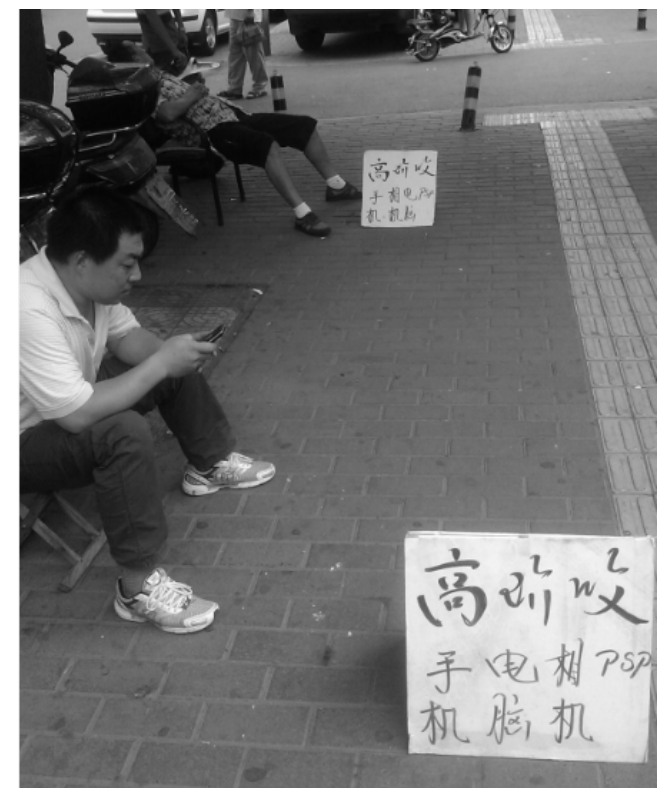

Fig. 3. Street ICT collectors and their signature boards

\section{Repair Markets and Second-Hand Shops}

Although there are many regulated repair shops in China, this study only targets the unregulated ones because of their direct connection to informal collectors. These unregulated shops are called repair shops from their outside advertising signage boards. However, most of them also sell second-hand appliances besides providing the repairing services. Therefore, these unregulated small shops can be named either repair shops or second-hand shops. Many repair shops are located on the same street hence forming informal second-hand markets.
It is worth noting that these unregulated shops tend to specialize into two different types by products, which shops are dealing with either large household appliances or ICT products. Large household appliances repair shops are often family-based; the layout allows them to repair products inside and sell them at their front yards. Fig. 4 Shows the form of front-yard sales by a large appliance repair shop. As indicated from owners of these shops, their main customers are individual second-hand users.

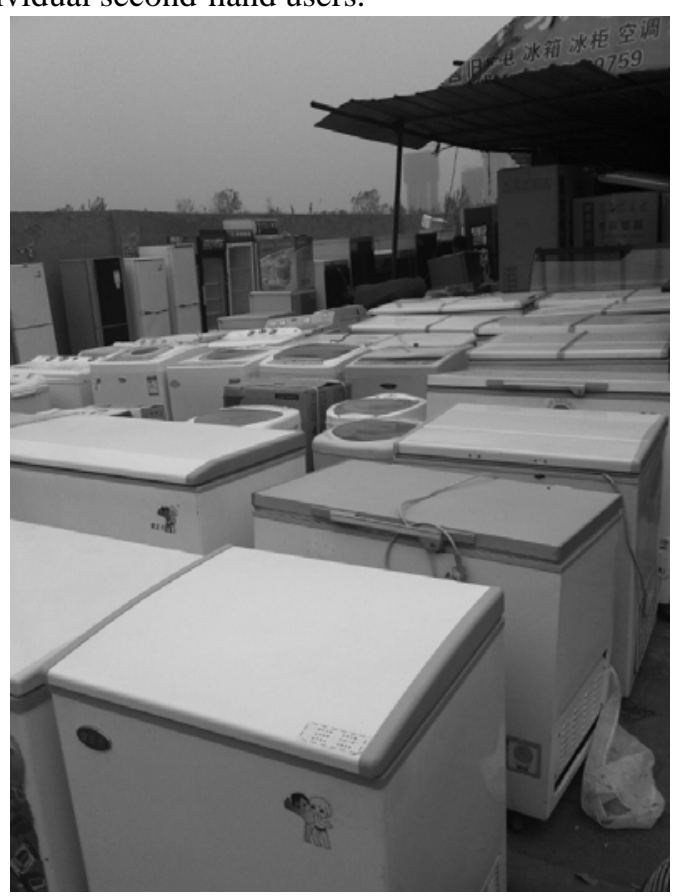

Fig. 4. Second-hand appliances sold in a repair shop.

\section{Component Supplier Shops}

These informal components supplier shops are often located in unobvious areas and normally only can been found by a local guide or a repair shop's recommendation. As observed, most customers come from repair shops or skilled individuals. Employees of these shops are vigilant to any unfamiliar visitors.

Components supplier shops offer various brand new and second-hand components. The price of components provided by these supplier shops is much lower than official component suppliers. It is understood that a cooling system within a water dispenser which costs $50 \mathrm{RMB}$ in most registered suppliers, is only $12 \mathrm{RMB}$ in one of the unregulated supplier shops.

\section{E. Collection and Distribution Centers}

While the repair shops and component suppliers specialize on repair and resale, the collection and distribution centers offer a wider range of services. These larger operations normally occupy large worksites and hire numbers of employees. Collection centers purchase any form of e-waste from a variety of sources, including institutions, households, informal collectors and repair shops. Generally, all collected products are sorted into three main groups: second-hand products that can be reused, irreparable larger appliances that wait for dismantling, and residual products and e-scraps waiting to be sold by the weight.

During informal conversations, employees in collection 
sites stated that PCs are the most popular products due to the high demand in second-hand markets. Compared with repair shops, whose customers are individual second-hand users, collection and distribution centers have regular larger wholesaler clients for monitors, TVs, washing machines, air conditioners and refrigerators. Many small-medium manufacturers wholesale monitors and then reassemble them into screens or Closed Circuit Televisions (CCTV). Most appliances are transferred to less developed regions such as Lang fang (Hebei province), Jinghai (countryside of Tianjin) and Inner Mongolia. Other than appliances with reuse values, many e-waste items are at most dismantled into materials such as plastics, metals, and glass. The rest of the residual waste, along with small equipment that hard to dismantle due to their compact structure (such as mobile phones), are sold by the weight to collectors from Guangdong. Fig.5 illustrates the e-scrap after dismantling and waiting to sell.

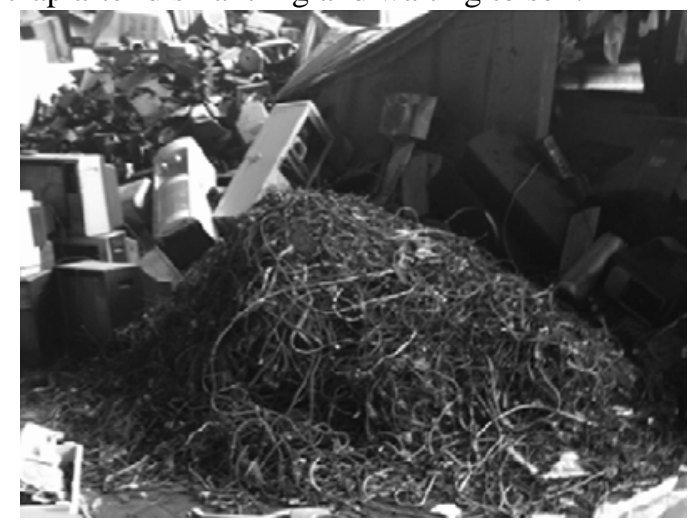

Fig. 5. Residual e-waste after dismantled and waiting to sell

\section{SUMMARY}

Results in this study indicate that most informal stakeholders in Tianjin are located in less-developed areas. Given the current understanding of the informal recycling system in Tianjin, the WEEE material flows and the relationship between informal stakeholders are demonstrated as Fig.6.

Several features of the informal recycling system have been identified by the present study. These are listed as bellow:

1) Reuse priority: as discussed above, all the informal sectors have been maximizing the reuse value of product/components because selling products as second-hand gains more profits than simply dismantling them. As a result, the quantity of e-waste declines gradually along the main line of informal recycling system (see left part of fig. 6). As illustrated, reusable products and components are drawing out by a reuse system.

2) Cheap labors and low costs of refurbishment: as discussed above, skills for refurbishment are necessary to all the informal sectors and even to the component supplier shops. Low prices of components and cheap labors lead to an overall low expenses of refurbishment, thus stimulating the booming of the second-hand markets in China.

3) Separated large appliances and ICT products reuse systems: as indicated in fig.6, large appliances and ICT products are respectively collected by two separate systems, based on different groups of collectors. Reuse and recycle of large appliances mainly depends on the individual door-to-door collectors, while reuse of ICT products depends on the street ICT traders. These two groups of collectors are important disposal options for Chinese households considering the lack of collection infrastructure in China. Similarly, the repair shop for large appliances and small ICT products are also separated.

4) Market-driven: from interview results, PCs are the most wanted appliances, followed by large household appliances in any condition. By contrast, ICT products can be reused only if in good-condition through the ICT street traders. Informal collectors' collection preferences are driven by the demands of the market.

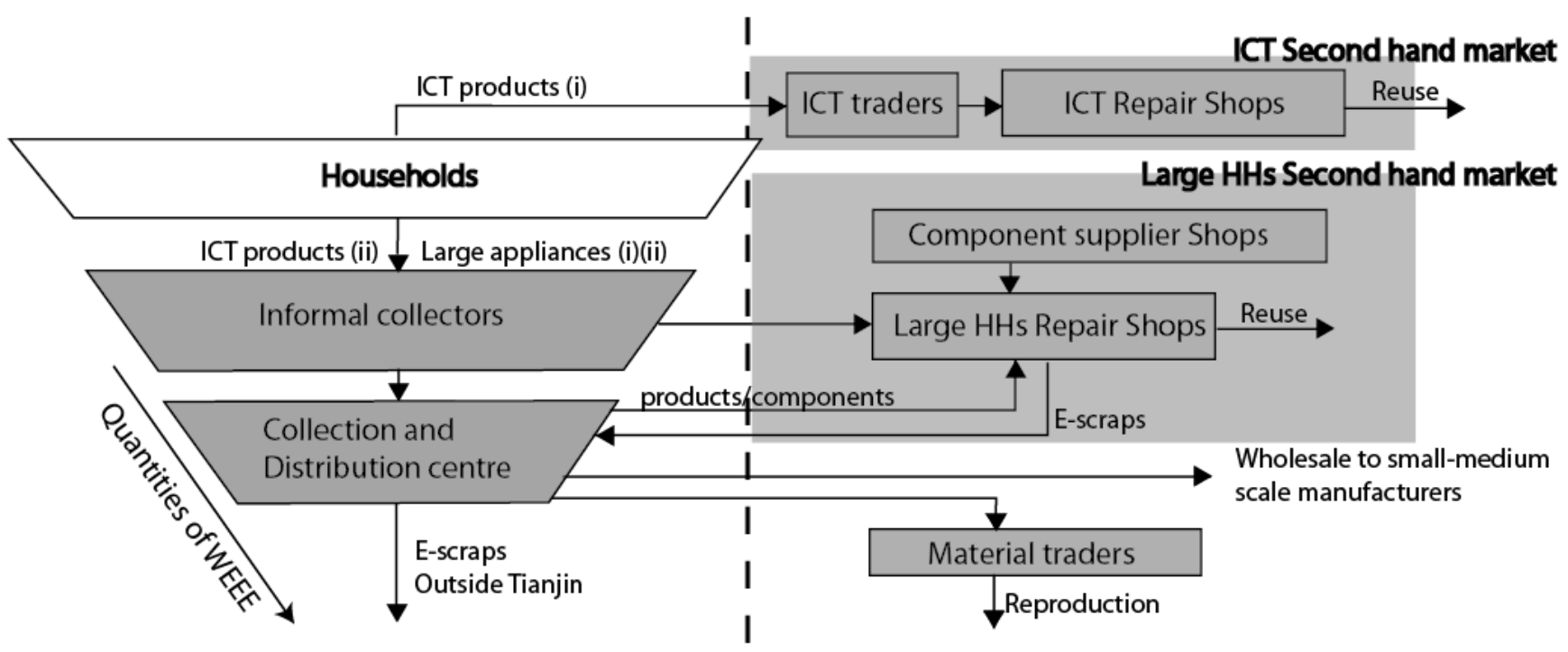

(i) products have reuse value (ii) products have no reuse value

Recycling system | Reuse system

Fig. 6. Electronic waste flows in Tianjin and the relationship between informal stakeholders. 


\section{CONCLUSIONS}

Although the study was limited to one regional city area in Tianjin, the results of this study reveal the characteristics of informal recycling sectors in a wider range of China. The informal recycling sectors use readily available and low cost tools, transportation and labor that also exist in many other regions in China. The spontaneity of the informal city-based e-waste collection and operations has many advantages that could be learnt by the regulated collection systems in China. The advantages include providing considerable job opportunities and economic contribution to local communities and reducing financial burden on regulated waste collection and management services. Most importantly, informal collection operations involve few activities that lead to environmental pollution.

In view of the advantages of informal collection system, it is a challenge for the Government to regulate or compete with the low cost, self-organized and distributed features of the informal sectors. Therefore, it is better to formalize informal collection sectors and encourage them to send collected e-waste resources to formal recycling plants, which equipped with environmental control facilities.

In addition, because the profits earned by informal sectors will be definitely influenced after the implementation of formalization, the Chinese Government could put more efforts on providing incentives. Furthermore, an extended producer responsibility (EPR) scheme which is specifically designed for the Chinese situation could offer a logistics collection network and financial support, and also establish an enforcement of WEEE regulation in China.

Considering the limited space available in this paper, most photos from the observational study have been omitted. A fuller account of this research is currently being completed as a $\mathrm{PhD}$ dissertation.

\section{REFERENCES}

[1] H. Kang and J. M.Schoenung, "Electronic waste recycling: A review of U.S. infrastructure and technology options," Resource, Conservation and Recycling, pp. 368-400, 2005.

[2] A. Terazono, "Management of E-waste and mixed metal scrap: current issues and future tasks," South Pacific Regional E-waste Workshop (ewaste2010) Sofitel Hotel, Brisbane, Australia,21 July 2010, 2010.

[3] F. Yoshida and H. Yoshida, "Japan, the European Union, and waste electronic and electrical equipment recycling Key lessons learned," Environmental Engineering Science, vol. 27, 2009.
[4] H. Boeni, U. Silva, and D. Ott, "E-Waste Recycling in Latin America: Overview, Challenges and Potential," Empa, Swiss Federal Laboratories for Material Testing and Research, Switzerland2006.

[5] T. Sakano, "Study of informal recycling business in Bandung, West Java, Indonesia," 2007.

[6] M. Streicher-Porte, R.Widmer, A. Jain, H-P. Bader, R. Scheidegger, S. Kytzia, "Key drivers of the e-waste recycling system: Assessing and modelling e-waste processing in the informal sector in Delhi," Environmental Impact assessment Review, vol. 25, pp. 472-491, 2005.

[7] B. H. Robinson, "E-waste: An assessment of global production and environmental impacts," Science of the Total Environment vol. 408, pp. 183-191, 2009.

[8] A. Sepúlveda, M. Schluep, F. G. Renaud, M. Streicher, R. Kuehr, C. Hagelüken, et al., "A review of the environmental fate and effects of hazardous substances released from electrical and electronic equipments during recycling: Examples from China and India," Environmental Impact Assessment Review, vol. 30, pp. 28-41, 2010.

[9] G. H. Xing, J. K. Y. Chan, A. O. W. Leung, S. C. Wu, and M. H. Wong, "Environmental impact and human exposure to PCBs in Guiyu, an electronic waste recycling site in China," Environment International, vol. 35, pp. 76-82, 2009.

[10] X. Chi, M. S. Porte, M. Y. L. Wang, and M. A. Reuter, "Informal electronic waste recycling: A sector review with special focus on China," Waste Management, vol. 31, pp. 731-742, 2011.

[11] J. Yang, B. Lu, and C. Xu, "WEEE flow and mitigating measures in China," Waste Management, vol. 28, pp. 1589-1597, 2008.

[12] European Communities, "Implementation of the Waste Electric and Electronic Equipment Directive in the EU," European Commission,Directorate-General Joint Research Centre,institute for prospective technological studies2006.

[13] R. Lu. (2008, 18th, Apr). The problem of E-waste [Online]. Available: http://www.china.org.cn/english/China/238544.htm

[14] K. Gërxhani, "The Informal Sector in Developed and Less Developed Countries: A Literature Survey," Springer vol. 120 pp. 267-300, 2004.

[15] H. Briassoulis, "Sustainable development and the informal sector: an uneasyrelationship?," Journal of Environment and Development, vol. 8, pp. 213-237, 1999.

[16] B. Guha-Khasnobis, R. Kanbur, and O. Elinor, "Beyond formality and informality," in Linking the Formal and Informal Economy: Concepts and Policies. , ed New York: WIDER Angle, 2006, pp. 1-4.

[17] D. C. Wilson, C. Velis, and C. Cheeseman, "Role of informal sector recycling in waste management in developing countries," Habitat International, vol. 30, pp. 797-808, 2006

[18] MOF, Chinese Ministry of Finance, "Trade-in measures for the implementation of Waste of household appliances " Chinese National Ministry of Finance, Commerce Departement of Chinese Government, National Development and Reform Commission,Ministry of Information Industry, Beijing, 2009.

[19] A. Terazono, A. Yoshida, J. Yang, Y. Moriguchi, and S.-i. Sakai, "Material cycles in Asia: especially the recycling loop between Japan and China," Material cycles and waste management in Asia, vol. 6, pp. 82-96, 2004

[20] M. B. Park, "Product Life: Designing for longer lifespans," 2009.

[21] T. Cooper, "Slower Consumption- Reflections on product life spans and the "Throwaway Society," Journal of Industrial Ecology, vol. 9, pp. 51-67, 2005. 